\title{
Correction to: MRI enhancement based on visual-attention by adaptive contrast adjustment and image fusion
}

\author{
Rui Zhu ${ }^{1,2} \cdot$ Xiongfei $\mathrm{Li}^{1,2} \cdot$ Xiaoli Zhang ${ }^{1,2}$ (D) $\cdot$ Xiaowei $\mathrm{Xu}^{3}$
}

Published online: 19 March 2021

(C) Springer Science+Business Media, LLC, part of Springer Nature 2021

\section{Correction to: Multimedia Tools and Applications (2020) https://doi.org/10.1007/s11042-020-09543-9}

Figure 13 in the original publication was incorrect. The original article has been corrected.

Publisher's note Springer Nature remains neutral with regard to jurisdictional claims in published maps and institutional affiliations.

The online version of the original article can be found at https://doi.org/10.1007/s11042-020-09543-9

\section{Xiaoli Zhang}

zhangxiaoli@jlu.edu.cn

1 Key Laboratory of Symbolic Computation and Knowledge Engineering of Ministry of Education, Jilin University, Changchun 130012, China

2 College of Computer Science and Technology, Jilin University, Changchun 130012, China

3 Department of Information Sciences, University of Arkansas at Little Rock, Little Rock, AR, USA 